\title{
“A alagação ofende!": considerações sociológicas acerca de um desastre silente no Alto Juruá, Acre, Brasil
}

\section{“The alagação offends!": sociological considerations about a silent disaster in High Juruá, Acre, Brazil}

Raquel Duarte Venturato-Landmann - Doutoranda em Ciências da Engenharia Ambiental pela Escola de Engenharia de São Carlos, Universidade de São Paulo (2014); pesquisadora do Núcleo de Estudos e Pesquisas Sociais em Desastres (NEPED), Departamento de Sociologia da Universidade Federal de São Carlos (UFSCar). E-mail: quelvento@yahoo.com.br

Norma Valencio - Doutora em Ciências Sociais pela Universidade Estadual de Campinas; coordenadora do Núcleo de Estudos e Pesquisas Sociais em Desastres (NEPED), professora dos Programas de Pós-Graduação em Sociologia da UFSCar e em Ciências da Engenharia Ambiental da EESC/USP. E-mail: normaf@terra.com.br

\section{Resumo}

Os desastres no Brasil têm sido cada vez mais frequentes. No entanto, a oficialização dos desastres em localidades remotas não está sendo feita a contento pela Defesa Civil. Assim, as práticas técnicas de resposta e reabilitação são insuficientes. Isso torna os desastres silentes, isto é, invisíveis socialmente. Com o intuito de torná-los visíveis, este estudo sociológico analisa um caso de desastre que ocorreu no ano de 2008, na região do Alto Juruá, estado do Acre. Com base em procedimentos de pesquisa qualitativa, o estudo contrapôs o discurso institucional através de registros oficiais e das narrativas dos moradores das comunidades ribeirinhas locais, obtidas através de pesquisa de campo.

\section{Palavras-chave}

Desastres. Defesa Civil. Amazônia brasileira. Povos da floresta. Alto Juruá. Acre.

\begin{abstract}
Disasters in Brazil have been increasing in the latter years. However, the official communication of disasters in remote places is not being done properly by civil defense. Therefore, practical techniques of response and rehabilitation are insufficient. This makes disasters become silent, i.e. socially invisible. In order to make them visible, this sociological study analyzes a disaster case occurred in the year 2008 in Alto Juruá region, state of Acre, Brazil. Based on qualitative research procedures, the study compares the institutional discourse, from official records, and the narratives of the local riverine communities obtained in field research.
\end{abstract}

\section{Keywords}

Disasters. Civil Defense. Brazilian Amazon. Forest people. Alto Juruá. Acre. 


\section{INTRODUÇÃO}

Um desastre não é somente um acontecimento factual, concreto, algo palpável. Especialmente para os grupos sociais implicados diretamente neste tipo de adversidade, aquilo que não é visível ou evidente a terceiros e nem passível de mensurações objetivistas, é o que mais conta para explicar a situação.

Há variadas interpretações em jogo e, não raro, em conflito, para definir o que é um desastre que solapa as rotinas da vida cotidiana de uma dada comunidade, a qual compartilha um território, e como proceder para remediar as perdas havidas. Embora o meio técnico privilegie o enfoque sobre um reduzido conjunto de elementos para, em relação aos mesmos, contabilizar os danos e prejuízos materiais - sejam eles públicos ou privados -, tais elementos ganham sentidos específicos para cada subgrupo social que deles dependia. Por exemplo, danos e prejuízos que envolvem instalações, equipamentos, estoques e arquivos de serviços de saúde, de educação, de saneamento básico, de eletricidade, de justiça, entre outros, implicam em diferentes desdobramentos deletérios para distintos segmentos de público e de demandas da vida social local. Na atividade econômica, perdas extensivas de meios e objetos de trabalho em estabelecimentos comerciais, industriais, agropecuários e de prestação de serviços podem perturbar a estabilidade de postos de trabalho, a circulação monetária, a solvência de compromissos financeiros, entre outros. Particularmente no que concerne à esfera privada, os significados mais apropriados em torno dos elementos danificados ou destruídos são os que emergem desde a autoexpressão das famílias, dentro de cada família, na particularidade de cada indivíduo, e assim por diante.

Enfim, quando há camadas de complexas relações de intersubjetividade, de sistemas de crenças, de regras e convenções sociais, que se sobrepõem e regulam as conexões entre o sistema de objetos e de ações que animam um dado território, tornando-o um espaço (SANTOS, 1997) ou, mais apropriadamente, um lugar identitariamente referido (ZHOURI; OLIVEIRA, 2010), a busca por uma interpretação dos desastres não deveria desconsiderá-las. Ao contrário, quando um dado sistema de objetos desmorona um lugar, isso repercute em toda a arquitetura social invisível.

É reconhecido que eventos hidrometeorológicos severos e extremos como secas e estiagens prolongadas, assim como chuvas intensas ou prolongadas, podem ser interpretados como perigos, incidindo sobre dado lugar, de modo a provocar distúrbios na sua dinâmica regular, isto é, perturbar as rotinas da vida prática no âmbito privado e público. No meio rural, isso envolve a possibilidade de que tais perigos gerem prejuízos momentâneos ou duradouros nas condições

Novos Cadernos NAEA • v. 17 n. $2 \cdot$ p. 239-264 • dez. 2014 
de circulação e tráfego de vias terrestres e fluviais, na inviabilização de afazeres domésticos; na obstrução do acesso e uso de pertences pessoais e coletivos, na impossibilidade de anteparo aos animais de estimação e no manejo dos animais de criação, nas restrições no trato das lavouras, na alteração do comportamento dos estoques pesqueiros e no esforço de pesca decorrente, entre outros. No entanto, é preciso atentar que o que torna tais eventos hidrometeorológicos um perigo concreto é a sua correspondência com a qualidade das estratégias governamentais e comunitárias para lidar preparativamente com os seus efeitos ou reabilitar-se diante da sua manifestação. Se a qualidade dessas estratégias for baixa, o perigo concreto depara-se com um meio social vulnerabilizado, e daí desenrola-se um processo que culmina num desastre. As estratégias mais adequadas são as que se apresentam como uma construção compartilhada (leiga e perita) de conhecimento sobre o potencial de perigo de certos eventos hidrometeorológicos e, desde aí, do apoio material e valorização ao desenvolvimento de habilidades próprias da comunidade exposta para proteger-se, contando com o respaldo do atendimento dos órgãos de emergência, nomeadamente das equipes multidisciplinares do meio técnico-operacional de defesa civil.

Este é apenas um aspecto de uma problemática mais abrangente, mas que aqui destacamos para referir duas armadilhas em que usualmente se cai, em busca da compreensão de um desastre: a primeira, que a materialidade da destruição ou danificação em um cenário se explique por si só, o que encobre processos ou relações que extrapolam essa circunscrição territorial; a segunda, que a explicação disponível, de caráter tecnocientífico, sobre eventos hidrometeorológicos seja automaticamente o mesmo que desvelar perigos, e que isso seja o mesmo que decifrar desastres, eliminando a busca de nexos explicativos nos processos socioculturais e sociopolíticos em que os sujeitos prejudicados estão inseridos.

Um dos caminhos para fugir dessas armadilhas seguramente é considerar como válida a interpretação dos referidos sujeitos, pois os mesmos podem dimensionar, a partir das suas referências culturais e de suas trajetórias de vida, o quão grave foi (ou é) o referido processo vivenciado na escala da comunidade, da família e do indivíduo. Apesar disso, a visão predominante do meio técnico-operacional de defesa civil costuma desprezar o ponto de vista desses sujeitos, e essa indiferença social faz parte do saber-fazer nos contextos de emergência no Brasil (VALENCIO, 2010a; 2014). Os grupos sociais afetados são vistos apenas como vítimas, cuja vocalização em torno dos acontecimentos é considerada desnecessária, pois os técnicos já saberiam como proceder naquelas circunstâncias, restringindo-se a um atendimento padronizado, conforme os protocolos construídos por processos institucionais herméticos. 
Assim, dentre outras indagações, ocorre-nos uma questão: Quão distantes têm sido as interpretações e as ações levadas a cabo pelo meio técnico-operacional de defesa civil diante daquelas que uma comunidade necessita quando atravessa um desastre?

Intentando dar pistas sociológicas sobre essa questão, partimos do estudo de caso de um desastre relacionado a uma enchente atípica, ocorrida no ano de 2008, na região do Alto Juruá, estado do Acre, na Amazônia brasileira. Contrapomos registros discursivos (documentais e de campo) que evidenciam as divergências entre a visão e a ação da defesa civil, e a das comunidades tradicionais ribeirinhas pesquisadas. Antes de debruçarmo-nos sobre o caso, apresentamos sucintamente as referências teóricas que subsidiaram a análise dos resultados da pesquisa documental e de campo.

\section{APONTAMENTOS PRELIMINARES ACERCA DO INCONCILIÁ- VEL DIÁLOGO ENTRE A TECNOCIÊNCIA E OS LEIGOS}

Na perspectiva foucaultiana, o discurso que embasa certas práticas de um sujeito social é uma forma simbólica de assegurar a sua dominância na relação com os demais. Em "A Ordem do Discurso", Foucault assevera:

Suponho que em toda sociedade a produção do discurso é ao mesmo tempo controlada, selecionada, organizada e redistribuída por certo número de procedimentos que têm por função conjurar seus poderes e perigos, dominar seu acontecimento aleatório [...] Em uma sociedade como a nossa, é certo, procedimentos de exclusão [...] O discurso não é simplesmente aquilo que traduz as lutas ou os sistemas de dominação, mas aquilo porque, pelo que se luta, o poder do qual nos queremos apoderar (FOUCAULT, 1996, p. 8-10).

No contexto contemporâneo de remodelação das instituições do Estado, a razão da tecnociência adquire predominância de ordenamento nos regimes de verdade. Aqueles que a representam, estruturam uma linguagem própria, que, ao mesmo tempo, lança e difunde uma interpretação nova sobre os desafios do mundo, e situa os seus representantes no topo das novas instituições públicas, a fim de que, desde lá, possam ter o controle de certos acontecimentos tidos como críticos, estratégicos e afins. $\mathrm{O}$ conceito foucaultiano de dispositivo auxilia no desvendamento dessas formas de controle social, pois alude a "qualquer coisa que tenha de algum modo a capacidade de capturar, orientar, determinar, interceptar, 
modelar, controlar e assegurar os gestos, as condutas, as opiniões e os discursos dos seres viventes" (AGAMBEN, 2005, p.13). No nível microssocial, no que tange ao propósito de reforçamento da ordem na vida social nos indivíduos, opera o poder disciplinador, o qual, entre outras práticas, produz uma concepção de desviante, que se coaduna com os que não se ajustam às regras produzidas pela ação estatal. No nível macrossocial, as instituições públicas passam a se mover por uma racionalidade burocrática e hermética, que se desconecta crescentemente dos sujeitos que dependem da ação pública para garantir os mais variados aspectos de sua humanidade.

Examinando as convergências entre Elias e Foucault, Moraes e Silva et al. (2014) identificam que ambos estavam preocupados com a interdependência entre os níveis micro e macrossocial nas relações estruturantes que passam pelo controle político dos corpos. Para Foucault, o poder, como relação social, estaria na capacidade de um dado grupo controlar circunstancialmente os recursos necessários ao outro, regulamentar as formas de acesso tidas como legítimas e, através disso, deter as condições de classificar (ou desclassificar) os sujeitos. Norbert Elias, por seu turno, atentou para evidências de que no contexto de emergência do Estado moderno, os camponeses já estariam submetidos a novos processos de assujeitamento devido a sua classificação como incivilizados, a quem "faltava modos" coadunados com a sociabilidade urbana em processo de dominância. Novas formas de opressão social surgiam, assim, pelos discursos, saberes e práticas dos que transformavam os costumes e controlavam as novas instituições.

Nunca é demais reiterar que o discurso da tecnociência não é neutro, pois opera assimetricamente sobre as decisões em torno dos rumos do desenvolvimento (FLORIANI, 2000). Ademais, em um contexto de incertezas e certezas contraditórias há pontos de vista inconciliáveis e assimétricos sobre os problemas socioambientais (GUIVANT, 1998), e sucessivas situações de desencaixe entre os sujeitos e os seus contextos concretos (GIDDENS, 1997).

Os desastres são um aspecto relevante na discussão da questão ambiental. E, no caso brasileiro, chama a atenção que a quase totalidade dos desastres oficialmente registrados estejam relacionados a eventos de estresse hídrico (secas e estiagens prolongadas) ou de chuvas (intensas ou prolongadas, com desdobramentos em enchentes, deslizamentos e afins) (BRASIL, 2012; EM-DAT, 2012; UNFCCC, 2007). Ocorre que o discurso que baliza as práticas do meio técnico-operacional atuante nos órgãos acionados nesse contexto especialmente dos órgãos de defesa civil, institucionalmente responsáveis pela 
coordenação das operações multissetorias, e tidos como peritos por excelência - é construído unilateralmente, com forte viés militar, o que deslegitima as tentativas de expressão alternativa de outros sujeitos acerca dos acontecimentos havidos, especialmente dos grupos sociais que participam dos desastres na condição tecnicamente descrita como "afetados". Esses são vistos, entre os leigos, como os mais desautorizados, posto que as provas objetivas da sua fragilidade, quando da exposição aos perigos, são traduzidas como fruto de ignorância, falta de consciência de risco, ausência de percepção de risco e afins (CARDOSO, 2006). E, portanto, gera-se uma forma de controle social na qual há uma impossibilidade política de produção de uma vocalização válida desses sujeitos sobre os acontecimentos que lhes dizem respeito. Resta-lhes, quando muito, apenas expressar objetivamente as suas descompensações quando são interpelados pela avaliação técnica especializada (na área de habitação, de assistência social, de saúde e outros), de um modo que fraciona e dissolve o seu drama, numa lógica de redutibilidade da vida e da política, frente à deterioração da mesma. E, assim, comunidades fragilizadas ou afetadas pelos desastres seguem inseguras quanto à resolução de seus problemas, que são capturados de forma fragmentada pelo ente público, bem como seguem temerosas quanto aos desafios e limites de suas iniciativas autônomas na busca de adaptação a contextos tão adversos.

A interação que o meio técnico-operacional atuante nas emergências espera que seja construída - isto é, idealizada - que, através da colaboração dos meios de comunicação, conseguem modelar no imaginário social - baseia-se na figuração herói-vítima. Nessa figuração, o desamparo ou o apuro súbito e inesperado vivenciado por uma dada comunidade tem como correspondência uma ação providencial do perito que vem em seu socorro ou auxílio. Se acaso a comunidade não aceite participar dessa figuração - seja porque se sinta igualmente proativa nas ações denominadas (tecnicamente) como "resposta" (por ex., no resgate de seus membros e na reabilitação mais imediata, como prover abrigo, alimentação e vestuário alternativo) ou porque se mantenha crítica em relação ao atendimento perito que recebe - um tensionamento social, tácito ou explícito, ganha feições. Dois aspectos desse tensionamento são a linguagem adotada pelas partes e as ações desarticuladas entre os lados envolvidos.

Vejamos isso num caso concreto de desastre relacionado a um evento hidrometeorológico descrito e analisado a seguir. 


\section{A INVISIBILIDADE DOS DESASTRES NO ACRE}

No Brasil, a "certidão de nascimento" de um desastre, no âmbito da comunicação interna e externa do aparato estatal com o restante da sociedade, é o Decreto Municipal declarando a emergência. O mesmo é publicado em veículo de comunicação de abrangência local ou regional, seguido da ciência dos níveis superiores de governo (estadual e federal). Quando o Decreto Municipal inclui documentos adicionais descrevendo os danos e perdas acima da capacidade imediata de resposta, constatando a situação de emergência (SE) ou o estado de calamidade pública (ECP) - é levado ao Ministério da Integração Nacional (MI), e este, através de ato da Secretaria Nacional de Defesa Civil (SEDEC), emite uma portaria de reconhecimento do desastre. Na referida portaria, publicada no Diário Oficial da União, são descritas sinteticamente as características espaciais e temporais sobre o desastre. O conteúdo desses documentos, bem como a sua tramitação no âmbito do Sistema Nacional de Proteção e Defesa Civil (SINPDEC), embasam as ações técnicas que já foram ou serão deflagradas, isto é, os recursos humanos e matérias que são e serão mobilizados para o atendimento à comunidade que se encontra no contexto de crise.

Nos registros oficiais do SINPDEC, o estado do Acre, localizado na Região Norte do país, parece relativamente isento de desastres, se comparado a outras unidades federativas.

A soma de portarias de reconhecimento dos desastres ocorridos no país, na forma de Situação de Emergência ou Estado de Calamidade Pública, no período 2004-2013, chega a 14.127. Ao distribuirmos as informações pelas macrorregiões do país, verificamos que a Região Norte corresponde a um dos menores números de ocorrências de desastres, tendo em conta a emissão de portarias federais. $\mathrm{Na}$ relação com os desastres nacionais, a Região Norte torna-se quase invisível: para as 1447 portarias federais do ano de 2004, apenas 7 foram da Região Norte; no ano de 2007, das 1096 portarias federais, o Norte comparece com somente 35 portarias; e no ano de 2013, das 1938 portarias federais, o Norte participa com apenas 55 portarias. Em relação ao Brasil e à Região Norte, no estado do Acre os desastres parecem ser ocorrências ainda mais esporádicas e ínfimas. No caso acreano, aparentemente se trataria de um tipo de ocorrência que, segundo as informações institucionais produzidas e tramitadas no interior do SINPDEC, e mesmo na escala regional, seria pouco frequente (Tabela 1). 
Tabela 1 - Total anual de portarias de reconhecimento federal de desastres (situação de emergência e estado de calamidade pública) no Brasil, na região Norte e no estado do Acre, no período de 2004-2013.

\begin{tabular}{|c|c|c|c|}
\hline Ano & Brasil & Norte & Acre \\
\hline 2004 & 1447 & 7 & 0 \\
\hline 2005 & 1511 & 73 & 0 \\
\hline 2006 & 789 & 14 & 1 \\
\hline 2007 & 1096 & 35 & 0 \\
\hline 2008 & 1028 & 14 & 0 \\
\hline 2009 & 1080 & 19 & 0 \\
\hline 2010 & 1912 & 136 & 1 \\
\hline 2011 & 984 & 48 & 2 \\
\hline 2012 & 2342 & 84 & 9 \\
\hline 2013 & 1938 & 55 & 5 \\
\hline TOTAL & 14127 & $\begin{array}{c}485 \\
(3,43 \% \text { do total geral })\end{array}$ & $\begin{array}{c}18 \\
(0,13 \% \text { do total geral, } \\
3,71 \% \text { do total da região })\end{array}$ \\
\hline
\end{tabular}

Fonte: sistematizado pelas autoras a partir das informações do site da Secretaria Nacional de Defesa Civil do Ministério da Integração Nacional (SEDEC/MI). Acesso em 14 de setembro de 2014.

Embora esse elenco de informações técnicas do âmbito institucional de defesa civil sinalize para uma arquitetura discursiva, na qual o Acre paira como uma espécie de "paraíso" de resiliência socioambiental, frente ao problemático contexto nacional de suscetibilidades aos inumeráveis perigos que concretizam milhares de emergências e desastres, convém adentrar em escalas menores de análise, a fim de investigar se porventura haveria desastres aonde os números oficiais não revelam.

Uma pista que facilita esse percurso é ver a água no centro dos perigos que, no contexto acreano, relacionam-se com o meio social e derivam em desastres. Ilustrativamente, no conteúdo das portarias de reconhecimento de desastres no período 2010-2013, observa-se que maioria das ocorrências está relacionada à água, seja pelo estresse hídrico, seja pelo abundante volume de chuvas (Tabela 2). Chama a atenção que no universo de 21 portarias de reconhecimento de desastres no período, 11 delas tipifiquem como desastres a ocorrência de "enchentes", isto é, um fenômeno hidrológico cíclico, que sempre esteve atrelado às características ambientais regionais e, em particular, ao modo de vida ribeirinho amazônico, tenha se transformado em um perigo. 
Tabela 2. Tipos de desastres, segundo as portarias federais de reconhecimento, no Estado do Acre, no período de 2010 a 2013.

\begin{tabular}{l|c|c|c}
\hline \multicolumn{1}{c|}{ Tipos de Desastres } & \multicolumn{3}{c}{ Acre } \\
\hline Doenças infecciosas virais & 2010 & 2011 & 2012 \\
\hline Enchente & 0 & 0 & 0 \\
\hline Enxurrada & 1 & 0 & 10 \\
\hline Estiagem & 0 & 0 & 1 \\
\hline Inundação & 0 & 0 & 1 \\
\hline
\end{tabular}

Fonte: Sistematizado a partir das informações do site da Secretaria Nacional de Defesa Civil do Ministério da Integração Nacional. Acesso em 20 de março de 2014.

Isso levanta algumas questões, dentre as quais destacamos: Que fatores levaram as enchentes a se tornarem um desastre no Acre? Por um lado, a forma acelerada de urbanização das maiores cidades acreanas tem sido similar ao que ocorre no restante das cidades na Amazônia brasileira, onde se destaca o inchaço das periferias urbanas desatendidas nos serviços de infraestrutura básica e demais políticas públicas. Por outro, tanto episódios ainda atípicos de aumento inesperado do volume precipitado nas cabeceiras das principais bacias quanto de secas vêm ocorrendo na Amazônia, e vários estudos (MARENGO, 2004; MARENGO, 2008a; 2008b; 2008c; MARENGO; VALVERDE, 2010; MARENGO et al., 2011) apontam para uma intensificação dessas ocorrências, relacionando-as a eventos extremos do clima. Se tais eventos se deparam com um meio social despreparado, os desastres se tornam inevitáveis, com episódios de falecimentos, lesões, danos materiais, modificações e interrupções de atividades econômicas e sociais, além da degradação ambiental (EIRD/ONU, 2007).

Há localidades acreanas em que as autoridades públicas estão mais predispostas a revelar a existência de desastres do que em outras. E o fazem através de decretos de SE ou ECP e das portarias federais correspondentes. Os desastres revelados e reconhecidos tecnicamente atestam que houve um processo precedente de desbalanço na dinâmica socioambiental e sociopolítica que chegou à sua culminância, corroendo de modo insuportável as rotinas de certos grupos sociais nos seus respectivos lugares, e que também houve insuficiência da capacidade de atendimento da defesa civil local (e de outros órgãos sob a sua coordenação/supervisão). Por exemplo, no período de 2010 a 2013, as portarias de reconhecimento de desastres no Acre, emitidas pelo Ministério da Integração Nacional, com base nos respectivos Decretos Municipais, relacionam-se a nove 
municípios do lado leste do estado, referente às Regionais do Baixo Acre, Alto Acre e Purus. Os municípios correspondentes estão identificados na Figura 1.

Figura 1 - Localização dos municípios com portarias federais de reconhecimento de desastres no estado do Acre, no período de 2010-2013.

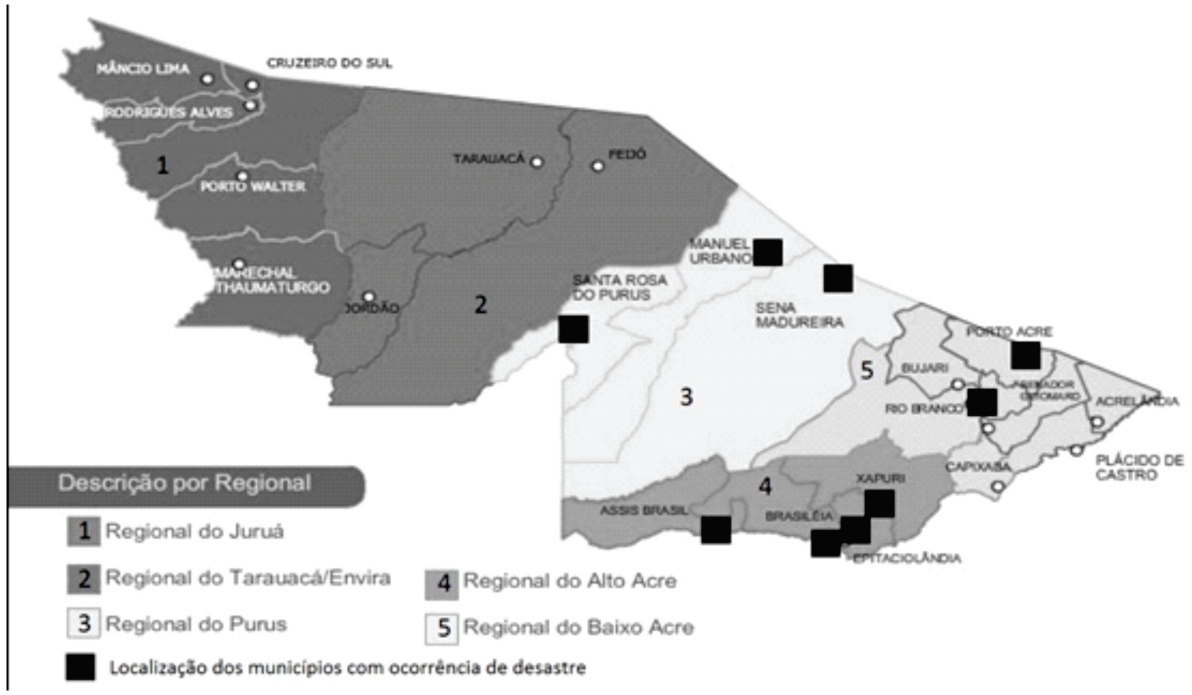

Fonte: http://www.ac.gov.br/wps/portal/acre/Acre/estado-acre/municipios

Estas informações parecem indicar que não há suscetibilidade a tal desbalanço na parte oeste do estado do Acre. Os motivos dessa resiliência poderiam ser variados. Uma hipótese seria a que certos eventos (como enchentes) não ocorressem naquela região; outra hipótese, a que esses eventos não se manifestassem na forma de perigos devido à existência de uma política de segurança humana plenamente compatível com as demandas socioambientais preventivas. Sendo estas hipóteses passíveis de descarte - tanto pelo histórico de altos volumes precipitados na região, contribuindo para os elevados volumes hídricos superficiais, quanto pelo histórico de abandono social por que passam as comunidades locais - outras hipóteses podem ser lançadas. Uma delas, sobre a qual nos debruçaremos, é a de que na referida região oeste acreana tenha ocorrido a invisibilização institucional de desastres. Isto significa dizer que: (a) eventos como enchentes de considerável magnitude estejam ocorrendo; (b) efetivamente, tais eventos se manifestem como perigos; (c) diante dos mesmos, a comunidade esteja suscetível; (d) a capacidade de atendimento do meio técnico-operacional local seja precária; mas que, apesar desses fatores, (e) haja uma comunicação oficial da ocorrência que esvazie a compreensão e o sentido da crise que está sendo vivenciada no território. Valencio (2010b) designa essa hipótese como a de 
desastres silentes, caracterizados por uma situação em que o agente pode a nomeálo oficial e publicamente, respaldando as providências urgentes para minimizar as adversidades ali surgidas no cotidiano do grupo social afetado - e não o faz.

Assim como ocorre em várias localidades do país, também no oeste acreano pode haver desastres silentes que destroem os meios de vida e as rotinas comunitárias; e ocorrem a despeito do discurso de reconhecimento da emergência e das práticas técnicas de resposta. No ano de 2008, na Regional do Juruá, um desastre desenrolou-se em paralelo às estatísticas oficiais de ocorrências de Situação de Emergência ou de Estado de Calamidade Pública, conforme o que ocorreu no município de Marechal Thaumaurgo.

\subsection{CARACTERIZAÇÃO SOCIOAMBIENTAL DE MARECHAL THAU- MATURGO}

O município de Marechal Thaumaturgo pode ser descrito como de pequeno porte, e voltado economicamente para o meio rural. Segundo o censo demográfico de 2010, a população total deste município compreende 14.227 habitantes, dos quais $27,90 \%$ residem na área urbana e 72,10\% residem na área rural. No período de 1991 a 2000, a taxa média de crescimento populacional anual foi negativa, de $-0,75 \%$, e no período decenal seguinte a população apresentou uma taxa média de crescimento anual da ordem de 5,11\%, o que mostra uma reversão positiva do processo de ocupação. A diminuição populacional municipal em uma década e o seu crescimento expressivo na seguinte, foram igualmente distintos do comportamento das taxas estadual e nacional, que orbitaram em crescimento positivo de apenas $1 \%$. A população de homens e mulheres em Marechal Thaumaturgo é relativamente equilibrada $(52,46 \%$ de homens e 47,54 de mulheres). Apesar da muito expressiva população rural, espalhada em comunidades que, na maioria, são ribeirinhas, essa forma de ocupação territorial vem decaindo: 96,85\% da população total em 1991 era rural, mas no ano de 2000, a população rural era 88,60\%, e no ano de 2010 compreendia 72,10\% (Tabela 3) (ATLAS..., 2013). 
Tabela 3 - População total por gênero, rural/urbana e taxa de urbanização município de Marechal Thaumaturgo (AC).

\begin{tabular}{l|c|c|c|c|c|c}
\hline População & $\begin{array}{c}\text { População } \\
\mathbf{( 1 9 9 1 )}\end{array}$ & $\begin{array}{c}\text { \% do Total } \\
\mathbf{( 1 9 9 1 )}\end{array}$ & $\begin{array}{c}\text { População } \\
\mathbf{( 2 0 0 0 )}\end{array}$ & $\begin{array}{c}\text { \% do Total } \\
\mathbf{( 2 0 0 0 )}\end{array}$ & $\begin{array}{c}\text { População } \\
\mathbf{( 2 0 1 0 )}\end{array}$ & $\begin{array}{c}\text { \% do Total } \\
\mathbf{( 2 0 1 0 )}\end{array}$ \\
\hline $\begin{array}{l}\text { População } \\
\text { total }\end{array}$ & 9.244 & 100,00 & 8.642 & 100,00 & 14.227 & 100,00 \\
\hline $\begin{array}{l}\text { População } \\
\text { residente } \\
\text { masculina }\end{array}$ & 4.762 & 51,51 & 4.547 & 52,62 & 7.463 & 52,46 \\
\hline $\begin{array}{l}\text { População } \\
\text { residente } \\
\text { feminina }\end{array}$ & 4.482 & 48,49 & 4.095 & 47,38 & 6.764 & 47,54 \\
\hline $\begin{array}{l}\text { População } \\
\text { urbana }\end{array}$ & 291 & 3,15 & 985 & 11,40 & 3.969 & 27,90 \\
\hline $\begin{array}{l}\text { População } \\
\text { rural }\end{array}$ & 8.953 & 96,85 & 7.657 & 88,60 & 10.258 & 72,10 \\
\hline $\begin{array}{l}\text { Taxa de } \\
\text { Urbanização }\end{array}$ & - & 3,15 & - & 11,40 & & 27,90 \\
\hline
\end{tabular}

Fonte: PNUD, IPEA e FJD apud Atlas de Desenvolvimento Humano, 2013.

Segundo o Censo local - realizado em junho de 2005 através do Cadastro Geral de Moradores -, na área da RESEX Alto Juruá foram identificadas 1.270 famílias residentes, com uma população de aproximadamente 8.000 pessoas, o que representa a maioria da população do município (se comparado tanto ao cômputo de 8642 habitantes no ano de 2000 quanto aos 14227 no ano de 2010). Essa população, em geral divide-se em 83 comunidades, distribuídas nos seis rios principais, quais sejam: o Amônia (6 comunidades), o Arara (4 comunidades), o Bajé (10 comunidades), o Juruá (33 comunidades), o São João (4 comunidades) e o Tejo (26 comunidades) (BRASIL, 2011). Afora essas comunidades, há moradores isolados que vivem próximos a outros cursos d'água, como na beira de lagos e igarapés. A população das Terras Indígenas no entorno da RESEX não está neste cômputo.

O modo de deslocamento usual dos moradores dessas comunidades é através dos rios, além de trilhas e varadouros que favorecem a comunicação terrestre entre as casas, como se fazia na época dos seringais, através das estradas de seringa (BRASIL, 2009; BRASIL, 2011).

O modo de vida ribeirinho amazônico na RESEX Alto Juruá não se resume a um modelo único de atividade, mas a um conjunto de atividades, das quais se destacam a caça, a pesca artesanal de subsistência, a agricultura tradicional e os pequenos extrativismos vegetais para o autoconsumo. 
A caça consiste na busca pelo alimento protéico mais apreciado no autoconsumo, cuja carne se consome com caldo de peixe e farinha de mandioca. O abate de um animal de criação (galinha, porco, carneiro, gado) só é empreendido quando não se logra êxito na caça. Os animais caçados para alimentação são divididos em duas categorias: caças e embiaras. As caças correspondem aos animais de grande porte, sendo os mais apreciados o veado, queixada, anta, caititu e paca. As embiaras correspondem aos animais de menor porte, dentre eles o macaco-de-cheiro, quatipuru, cotia, nambu, dentre outros. O período preferencial de caça é o de chuvas (inverno), que permite seguir as pegadas dos animais no solo. Pescar ou mariscar, como denominam os moradores locais, consiste em capturar espécimes de peixes, preferencialmente na época do verão, quando os rios estão com baixo nível de água e a captura é facilitada. Essas atividades envolvem homens, mulheres e crianças, e podem ser realizadas nos paranás, nos rios, nos lagos e também nos igarapés. Nos ambientes distintos mariscam-se diferentes espécies de peixes. A pesca ou mariscagem do mandim corresponde a uma atividade de grande mobilização. No verão - ou na seca - os cardumes se deslocam rio acima (a montante), em busca de locais mais profundos, como os lagos. Nesta época, os moradores da RESEX Alto Juruá se organizam comunitariamente para realizar a pesca do mandim. A atividade agrícola é praticada para fins de subsistência, e uma pequena parte excedente é destinada à comercialização. A cultura de maior relevância é a da mandioca, da qual se extraem vários subprodutos, tais como a farinha, a goma, a tapioca, o beléu (pé-de-moleque), o bolo de massa (buba) dentre outros produtos que podem ser feitos a partir do plantio e colheita da mandioca. O plantio de mandioca é quase sempre associado a outros plantios, como é o caso do milho e da banana. Durante o cultivo do milho, são feitas duas colheitas: uma referente ao milho verde, destinado ao consumo de subsistência, no preparo da canjica; e outra do milho maduro, destinado à criação de pequenos animais, principalmente aves, como galinhas e patos (BRASIL, 2011).

Há também moradores das margens do rio Juruá que compram farinha no comércio urbano de Marechal Thaumaturgo, pelo fato de preferirem se dedicar a outros cultivos, como é o caso do cultivo de feijão e de tabaco, destinados à comercialização. As áreas de várzea comportam cultivos de ciclos curtos, como é o caso do feijão, do pepino, da pimenta e de algumas espécies de macaxeira. 
Com relação ao relevo, este é caracterizado por duas formações principais, que correspondem à terra firme e à várzea. A terra firme configura-se como uma área marcada pelo processo erosivo sobre a Formação Solimões ${ }^{1}$. A várzea, por seu turno, é constituída pelas planícies aluvionares e terraços da bacia de sedimentação do rio Juruá. A predominância na área da RESEX Alto Juruá é da terra firme, e a várzea se estende pelo rio Juruá e em alguns pontos do rio Tejo. No quesito geomorfologia, a terra firme é caracterizada por sucessivas elevações - colinas, cristas e tabuleiros (terraços), enquanto que a várzea corresponde a uma planície de deposição sedimentar recente nas margens dos rios (planície de inundação) (BRASIL, 2011). Os rios que formam a Bacia do Juruá são sinuosos e possuem poucos trechos retilíneos, que e no linguajar local são denominados, de voltas e estirões respectivamente, (BRASIL, 2011). Outros regionalismos são usados para designar os leitos dos rios: espraiados ou de praias e os paranás.

O primeiro tipo, característico dos rios principais como Tejo e Juruá, são leitos de corte retangular, marcados pelas praias onde predomina a sedimentação, em uma margem; e o barranco na outra margem, onde predomina a erosão. Nesse tipo de rio também ocorrem os trechos de estirão. Durante o período das secas o fundo do leito fica bastante raso e de difícil navegação por essa caraterística aplainada, porém também é marcado pela existência de canais mais profundos, próximos às margens em erosão. Já os "paranãs" são rios cujos leitos tem corte mais abaulado, ocorrendo sobre uma região de rochas da Formação do Solimões. Nos paranãs os barrancos são altos e por vezes, nas cheias maiores, grandes regiões de floresta são inundadas (BRASIL, 2011, p. 19).

O ambiente de várzea também recebe subdenominações segundo o conhecimento tradicional. A várzea baixa corresponde às áreas que são inundadas durante o inverno, no período chuvoso, enquanto que a várzea alta designa os terraços recentes e antigas planícies aluvionares. Os baixos são as planícies de inundação de igarapés menores, localizados no interior das florestas.

Estiagens severas ou secas, assim como chuvas intensas e as correspondentes cheias extremas que suscitam, são (ainda) eventos ímpares na dinâmica ecossistêmica regional e, quando ocorrem, desorganizam as rotinas das comunidades ribeirinhas, especialmente no que concerne aos afazeres públicos, ligados às atividades de trabalho supracitadas, bem como aos afazeres de natureza privada (cuidados com a moradia, com os filhos etc.). Por isso, não há um habitus

\footnotetext{
1 "A Formação Solimões é descrita com abundância de dados sobre o Alto Rio Juruá (no trecho Cruzeiro do Sul - Foz do Breu) por RADAMBRASIL (1977, p. 48-54). Uma nova síntese dos dados geológicos foi elaborada pela Divisão de Geologia do IBGE e publicada em 1994 (IBGE; IPEA, 1994). O Projeto de Pesquisa e Monitoramento - USP/UNICAMP realizou estudos geológicos e geomorfológicos de 1994 a 1996" (BRASIL, 2011).
}

Novos Cadernos NAEA • v. 17 n. 2 • p. 239-264 • dez. 2014 
comunitário já consolidado para lidar com essas situações. O mesmo está em construção, valendo-se da grande flexibilidade e sintonia cultural com a dinâmica dos sistemas bióticos e abióticos regionais.

Mesquita (2012) descreveu a interpretação comunitária sobre os diferentes tipos de chuva na região do Alto Juruá. Porém, não mencionou o tipo de chuva que se revela nos relatos comunitários como um evento atrelado às enchentes excepcionais e, devido à fragilidade local, aos desastres. Trata-se da chuva grossa, correspondente a uma chuva contínua, ininterrupta e muito volumosa. É importante reiterar que nem toda chuva é indício de um desastre à espreita. E, ainda, observar que desastres relacionados a inundações graduais ou súbitas podem derivar de precipitações severeas ou desgelos havidos noutro território a montante, e não imediatamente no território da comunidade que sofre os efeitos perversos da elevação exagerada das águas que disso resulta.

Antes das grandes cheias ocorridas em 2009 e da seca de 2010 na região do RESEX Alto Juruá, eventos sobre os quais climatologistas se detiveram (MARENGO et al., 2011), em 2008 houve uma temporada de chuva grossa, que se associou a enchentes excepcionais.

Estranhamente, as autoridades locais de Marechal Thaumaturgo não decretaram situação de emergência (SE) ou estado de calamidade pública (ECP). Isso significa que tecnicamente havia a interpretação de que a capacidade de enfrentamento local dos perigos - incluindo principalmente as possibilidades de atendimento técnico de defesa civil diante das eventuais demandas era adequada, e que, portanto, não havia um desastre em curso. Porém, as comunidades tradicionais ribeirinhas na zona de amortecimento e no interior da Reserva Extrativista (RESEX) Alto Juruá vivenciaram os desdobramentos dessa enchente atípica como um perigo, frente às susceptibilidades que desencadearam um desastre e que a falta de apoio técnico para minimizar os danos circunstanciais e estruturais foi um fator agravante, que exigiu dos comunitários esforços extraordinários para mitigá-lo. Essas enchentes são conhecidas no repertório local como alagação.

\subsection{A INVISIBILIDADE DE UMA ALAGAÇÃO NO ALTO JURUÁ}

Em caso de enchentes, o Plano de Contingência para Enchentes e Queimadas Florestais, da Defesa Civil de Marechal Thaumaturgo, dispunha que a sua "finalidade consiste em estabelecer procedimentos-padrão reguladores de conduta dos Órgãos Setoriais” (PLANO DE CONTINGÊNCIA..., 2012). Isso 
significa que, em circunstâncias de enchentes ou inundações graduais naquela localidade, mobiliza-se, em tese, a integração do Sistema de Defesa Civil, por meio dos Órgãos Setoriais na esfera municipal, em parceria com a Defesa Civil do Estado, a fim de providenciar ações de resposta às conquências havidas. Como forma de obter informações sobre a efetividade dessas recomendações, busca-se as interpretações daqueles que, tendo se sentido expostos temerariamente aos perigos, deveriam ter sido atendidos, de modo que se sentissem protegidos.

Quatro anos após o desastre relacionado à alagação de 2008, buscou-se in loco a memória social das comunidades ribeirinhas da RESEX Alto-Juruá e da zona de amortecimento acerca da sua vivência naquele acontecimento trágico. De forma aleatória, foram colhidos relatos orais de 21 moradores adultos (10 mulheres e 11 homens) de sete comunidades. Na zona de amortecimento da RESEX, foram colhidos dois relatos. No interior da RESEX, os relatos foram colhidos nas comunidades de: Acuriá (2 relatos), Belfort (3 relatos), Arenal (4 relatos), Caipora (4 relatos), Pedra Pintada (3 relatos) e Vila Foz do Breu (3 relatos), esta última já na divisa com as Terras Indígenas Ashaninka e Kashinawa e na fronteira com o Peru (Figura 2).

Figura 2 - Mapa da rota percorrida no Rio Juruá.

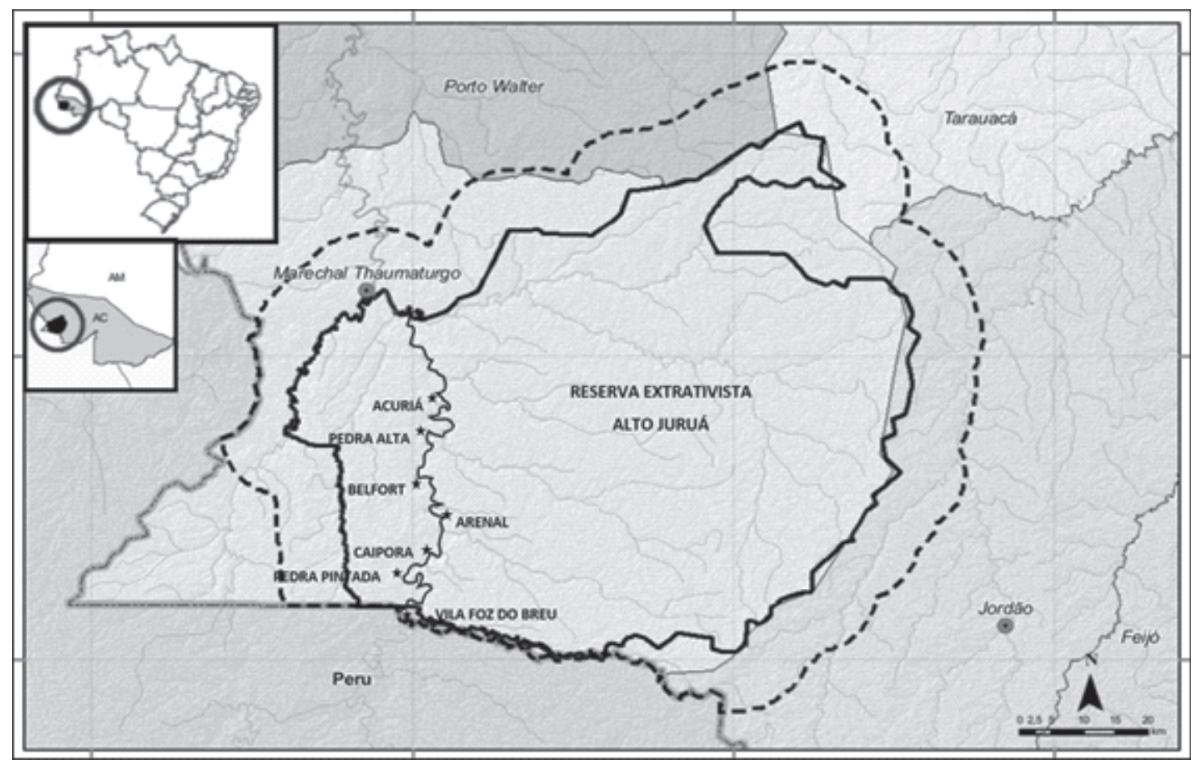

limites da RESEX

zona de amortecimento

Fonte: Mapa Político (BRASIL, 2011), adaptado pela primeira autora (2014). 
Os seis aspectos focalizados na abordagem aos moradores foram:

- as primeiras impressões diante da enchente atípica;

- as estratégias de enfrentamento dos perigos;

- os motivos atribuídos às perdas materiais havidas;

- as dimensões simbólicas dessas perdas;

- as enfermidades que apareceram após a alagação;

- os provimentos institucionais recebidos.

A seguir, esses aspectos serão descritos e analisados sucintamente, de modo integrado. O quadro esquemático com os trechos mais significativos dos relatos em relação aos aspectos supracitados encontra-se no Anexo 1.

\subsection{1 “A alagação ofende!"}

No modo de vida ribeirinho amazônico das comunidades da RESEX Alto Juruá e da zona de amortecimento, que se caracterizam como povos tradicionais da floresta, o universo público e privado interpenetram-se continuamente.

O conceito de povos e comunidades tradicionais pode ser compreendido como um conjunto de hábitos diferenciados que reproduz historicamente as particularidades do seu "modo de vida, de forma mais ou menos isolada, com base na cooperação social e relações próprias com a natureza" (DIEGUES, 2000). Little (2002, p. 23) atribui o conceito de povos tradicionais tanto a uma dimensão empírica de saberes e modos de fazer, quanto a uma dimensão política, na legitimação dos seus regimes de propriedade comum e das leis que os fundamentam. Dessa forma, os povos e comunidades tradicionais em questão são caracterizados pelo modo de vida camponês, entendido como aquele "constituído a partir de relações pessoais e imediatas, estruturadas em torno da família e de vínculos de solidariedade, de parentesco, tendo como unidade social básica a comunidade” (MARQUES, 2004).

Como a economia comunitária ribeirinha do Alto Juruá é essencialmente de autoconsumo, os hábitos alimentares dos membros das famílias designam a relação com o solo (plantio de espécies principais e temperos), com os animais de criação (de pequeno e grande portes), de caça e de extração (pesca), assim como a adaptação cronológica desses afazeres com as rotinas domésticas de convivência e de cuidado com o espaço do lar. No convívio comunitário, reforçase o aprendizado das técnicas e habilidades do trabalho, que moldam o corpo, assim como se consolidam as regras de uso do espaço comum na água e em terra firme. Muitas atividades realizadas em âmbitos distintos, público e privado, só 
o são em sintonia com a dinâmica do ecossistema peculiar, tornando o lugar e os sujeitos únicos e indissociáveis, embora mutantes. Assim como o lugar não é uma posição territorial no sentido estrito, mas uma expressão especializada do sujeito, segundo o território que habita (INGOLD, 2000). As identidades coletivas dos povos da floresta e seus universos simbólicos correspondentes são aludidos por práticas singulares que, no caso em tela, fundem o indivíduo, a família e a comunidade.

Nos relatos da maioria dos moradores ribeirinhos entrevistados transparece o relativo ineditismo da sua vivência direta de um evento de enchente atípica, denominada no linguajar regional como alagação. Alguns mencionam que essa alagação guardaria similaridade com outro evento ocorrido há décadas, presente na memória do grupo familiar ou na lembrança de uma geração anterior. De qualquer modo, o evento é tratado não apenas como algo inusitado, mas como um perigo concreto para as rotinas da vida cotidiana, bem como para a garantia dos meios fundamentais da vida local. É esse o sentido do discurso coletivo em torno da 'ofensa' da alagação. A alagação ofende "porque a gente ainda não sabe como lidar com ela", como sintetiza um dos entrevistados.

No que se refere às perdas relacionadas à alagação de 2008, a totalidade dos relatos faz referência aos objetos tanto circunscritos à esfera privada quanto à esfera pública da vida social. A 'ofensa' relacionada à alagação trata do sofrimento social derivado da simultaneidade das perdas nessas esferas, gerando uma súbita e imprevista deterioração global no plano material da vida individual, familiar e comunitária.

No que concerne à esfera da vida privada, foram destruídos ou danificados bens de uso pessoal (como vestuário), de uso doméstico (como móveis, eletrodomésticos, alimentos) e objetos de memória (como fotografias de entes queridos já falecidos, de rituais de passagem etc.), mas, destaca-se principalmente a ameaça da alagação sobre a moradia em si. Quando a casa é, que é afrontada pela força das águas, gera um medo aterrador, pois a casa é simbolizada como a fortaleza que defende os moradores das forças hostis (TUAN, 2005) e que, ademais, é um pedaço da identidade do grupo. $\mathrm{Na}$ topoanálise empreendida por Bachelard (2003), a casa confere os mais profundos níveis de segurança do indivíduo e do grupo convivente, pois é o espaço do recolhimento do corpo e do recolhimento interior, da restauração física e psíquica; assim, na perspectiva do referido autor, quando a casa luta contra a tempestade, a isso corresponde uma luta do mundo simbólico e subjetivo. Manter a casa a salvo dos perigos é garantir o ancoradouro da vida privada e da segurança psicossocial (VALENCIO, 2010b). Marandola Jr. (2014) salienta que habitar é a própria ação de ser-e-estar-

Novos Cadernos NAEA • v. 17 n. $2 \cdot$ p. 239-264 • dez. 2014 
no-mundo, e a prática através da qual "é possível ter segurança ontológica, garantindo a própria condição humana, a construção da autoidentidade e o desenvolvimento existencial da pessoa, da família, do lugar".

$\mathrm{Na}$ esfera pública da vida social, destacam-se as perdas econômicas de grande significado, isto é, referentes à destruição ou danificação dos meios de vida, expressos tanto nos roçados destruídos quanto nos animais de criação (mortos, feridos ou adoecidos) e nos petrechos de pesca (tarrafas e afins). Além desses, foram referidos os 'pés de fruta' no entorno da moradia, que tinham grande importância na dieta familiar corriqueira, além de compor um espaço paisagístico ao redor da casa, de valor grande valor simbólico.

De um lado, a similaridade entre os elementos materiais que as famílias de diferentes comunidades do Alto Juruá viram deteriorar, e que lhes pertenciam, permite confirmar a existência de um modo de vida comum, que o desastre momentaneamente pôs a pique. A economia familiar de autoconsumo caracterizava-se pela dedicação às lavouras temporárias de pequena escala (em culturas como o feijão, o milho e a mandioca), à criação de aves, suínos, bovinos e à pesca artesanal, em ambos resultava um pequeno excedente comercializável. A perda generalizada desses meios no desastre de 2008 implicou, assim, na necessidade familiar e comunitária de dependência circunstancial para obtenção desses alimentos, por meio de doações. E a cesta básica fornecida pelas autoridades locais a algumas famílias afetadas não continha itens totalmente compatíveis tanto com o tipo de produto como na quantidade necessária ao abastecimento familiar. A alternativa à doação era a aquisição de alimentos no mercado, e essa aquisição estava condicionada aos meios de pagamento disponíveis na família. Ocorre, no entanto, que o desastre comprometeu a geração de produtos agropecuários excedentes, inviabilizando a obtenção de renda monetária compatível com as necessidades de aquisição de alimentos e outros bens como itens de limpeza doméstica, higiene pessoal, transporte (gasolina para motor), vestuário e afins.

De outro, vale ressaltar que as formas de sociabilidade e o habitus atrelado ao modo de vida caboclo e ribeirinho forneceram às comunidades locais um repertório de possibilidades mitigadoras, do qual pudessem lançar mão em prol do socorro imediato. As estratégias adotadas para contornar as perdas e danos foram, dentre outras: correr para pegar os animais de estimação e criação, levando os primeiros consigo e colocando os últimos numa terra mais alta; subir o assolhado da moradia e elevar o mobiliário e eletrodomésticos o mais alto possível; matar os animais silvestres que ameaçam atacar a família dentro da moradia ou do acampamento; montar acampamento nos terrenos mais elevados, próximos à moradia; ir para a casa de parentes em áreas mais seguras; se a casa 
estivesse mais segura, acolher as demais famílias da comunidade que não tivessem para onde ir; amarrar a casa para que a correnteza não a levasse embora, ou amarrar a casa a uma embarcação, para então arrastá-la até outra margem onde a correnteza fosse mais fraca.

Por outro lado, para além da perda das coisas em si, as narrativas destacaram a dolorosa experiência de privação, ou seja, a sensação de degradação identitária e do viver subjacente ao processo de descarte involuntário ou de ver as coisas se deteriorarem incontrolavelmente. Expressões como "as coisas foram embora", "ficamos sem", "tivemos que jogar tudo fora", "perdemos tudo", "perdemos a coragem", "perdemos a vontade de viver", entre outras, retratam um universo material em colapso, que mobiliza o mundo subjetivo e simbólico de várias formas. Embora o muito que tivessem mobilizado com esforço individual, familiar e comunitário para se manterem vivos no auge do contexto adverso, bem com a sobrecarga de trabalho que assumiram nos meses subsequentes para se recuperar num patamar mínimo aceitável, nas narrativas sobreveio a memória da tristeza, do adoecimento, do medo; o sentimento de vazio existencial e a perda de confiança na capacidade de recuperação. A humilhação experimentada naquele momento e as incertezas quanto ao futuro foram o cimento dessa memória social sobre o desastre. As coisas municiavam as práticas sociais da vida cotidiana. Assim, uma vez que as coisas foram perdidas, debilitou-se sobremodo o exercício das práticas sociais correspondentes, afrontando a dignidade dos respectivos sujeitos atuantes, que se mesmos submeteram a dormir sem o colchão, cozinhar sem o fogão, alimentar-se frugalmente e sem atender às suas preferências e hábitos, vestir roupas alheias, prescindir de hábitos de higiene, lidar com o desafio de recuperar os meios de trabalho, sem condições monetárias de reposição, e assim por diante.

Os motivos atribuídos às perdas materiais foram de natureza variada, desde a sucessão de chuvas grossas ("uma atrás da outra"), do tempo de duração desses eventos ("dia e noite sem parar"), até a celeridade da cheia correspondente (“a água subiu muito rápido"). De qualquer modo, focalizam o aparecimento de um perigo tido como natural e inusitado. E, neste sentido consideraram que as práticas comunitárias de resposta estavam aquém do exigido pelas circunstâncias.

Algumas enfermidades ocorridas com os membros da família também aparecem nos relatos, em associação à alagação (ou logo após ao evento), como diarreias, gripes, febre e hepatite. A ingestão da água do rio ou de plantas que ficaram imersas foi apontada como uma prática relacionada a episódios de adoecimento humano e animal. 
Por fim, os moradores relataram que não foram informados previamente sobre os riscos e, que durante a crise aguda, os provimentos institucionais recebidos foram insuficientes. Teria havido a já mencionada distribuição desigual da cesta básica - denominada regionalmente como 'sacolão' -, quando os agentes públicos que trafegavam pelas vias fluviais paravam ocasionalmente na localidade para prestar atendimento emergencial. A comunicação informal entre os moradores de diferentes comunidades aguçou a percepção local de que não havia critérios bem estabelecidos para a distribuição dos alimentos pelo ente público, e que o desabastecimento preponderou. A indignação relativa não apenas à desigualdade na repartição dos víveres, mas também à injustiça no modo de distribuição, foi parte constitutiva do sofrimento dos moradores locais, pois se sentiam invisíveis socialmente e desamparados na sua relação com o Estado.

Enfim, os prejuízos aqui elencados foram vividos pelas famílias de tal modo que não vislumbravam receber o socorro institucional devido, tanto no tempo de reação quanto nas providências adotadas. Tampouco enxergavam um horizonte de reposição em curto ou médio prazo, por meio de esforço próprio. Isso implicou constatarem o seu mergulho em uma crise aguda e cronologicamente muito mais duradoura do que o evento hidrometeorológico em si. Considerando a definição de desastre como um acontecimento trágico e circunscrito a um tempo social demarcado pelos grupos afetados (QUARANTELLI, 1998; 2005), o desastre no Alto Juruá teve uma durabilidade maior do que a alagação, que foi o elemento de perigo, que se manifestou como tal, diante da fragilidade social preexistente. Neste aspecto, convém destacar que, embora o meio técnico-operacional de defesa civil costume denominar o pós-evento como sinônimo de pós-desastre, essa 'confusão' tem servido apenas como uma forma de dominação social, agindo para escamotear a importância dos dramas que continuam a se desenrolar quando as águas baixam. Os desdobramentos do conjunto de perdas levaram as famílias a um risco de empobrecimento e de desfiliação social.

Em contraponto a um silenciamento institucional, com a não decretação da emergência e nem o atendimento institucional local à altura da demanda social, o conjunto das narrativas revelam o vivenciamento de um desastre. $\mathrm{O}$ desastre silente manifestou-se neste caso através da discrepância entre a forma como as comunidades do Alto Juruá viveram a alagação do ano de 2008 - de comunidade em comunidade, ecoando a narrativa "perdermos tudo!" - e a forma como as autoridades conduziram a definição da situação e as práticas diante da mesma. Para as comunidades, o acontecimento trágico deixou muitas marcas em suas vidas. Para as autoridades não, a começar pelo fato de que a ausência do registro documental devido - de decretação da emergência e, em decorrência, da 
respectiva portaria federal de reconhecimento -, excluiu o caso das estatísticas oficiais. Ao sonegar o caso de Marechal Thaumaturgo na contabilização institucional dos desastres nos três níveis do SINPDEC (municipal, estadual e federal), as providências de atendimento (resposta e recuperação) ficaram aquém do demandado pelas comunidades, segundo o olhar destas acerca das suas próprias circunstâncias.

\section{CONCLUSÕES}

Do ponto de vista sociológico, a busca por uma explicação de um desastre exige o delineamento dos sujeitos e das relações estabelecidas entre estes. Somente assim vislumbrar-se-á o sistema de poder que os integra assimetricamente.

O meio institucional de defesa civil é historicamente avesso a considerar o ponto de vista de comunidades fragilizadas, que estão expostas aos perigos dos mais diversos tipos. Além de um recorte de classe na resistência a essa escuta, há o recorte que opõe peritos a leigos. No estrato dos leigos sem recurso de voz, destacam-se os povos tradicionais, cujo conhecimento empírico é culturalmente ainda mais distante e estranho ao contexto moderno, no qual os peritos emergiram e são legitimados em termos macrossociais. No tema dos desastres, o estranhamento entre leigos e peritos toma um caráter de conflito escamoteado, mas que se desvela em relação à forma como o meio institucional interpreta e age diante dos acontecimentos, e como as comunidades expostas interpretam, vivenciam e reagem aos perigos que lhes surpreendem.

Quando a visão institucional sobre um desastre é branda, a ponto de invisibilizá-lo, medidas práticas igualmente pouco incisivas e pouco eficazes em prol da proteção comunitária a acompanham. Medidas peritas esquálidas levam a comunidade exposta a fazer tudo que pode visando a sua proteção. Porém, apesar da ampla mobilização autônoma e espontânea, que revela os traços de uma solidariedade local consistente, esta pode ser insuficiente. Os prejuízos de toda ordem para a comunidade multiplicam-se quando são invisíveis ao ente público, como no caso do Alto Juruá.

Será isso fruto de um mero choque circunstancial de visões, em que uma das partes eventualmente se equivocou sobre a dimensão da crise socioambiental aguda, sem intentar fazê-lo? Talvez o caso em si pudesse apontar para que sim, isto é, um equívoco que deve ser entendido como uma exceção à regra. Contudo, tendo como base o modus operandi unilateral e impositivo da racionalidade técnico- 
científica de defesa civil, cujos dispositivos acionados servem para repudiar as diferenças e os diferentes, esse desencontro não é uma mera casualidade.

O processo arrasador e funesto de invisibilização e deslegitimação dos direitos territoriais dos povos tradicionais da floresta, que o Estado gera através das suas práticas modernizadoras diretas e indiretas, é um sinal inequívoco de que a falta de comunicação de um desastre a esses povos e o atendimento insuficiente às suas demandas de reabilitação não são coincidências, mas uma relação de poder. Desta relação, em que o neodesenvolvimento (expressão cunhada por BOITO Jr., 2012) na Amazônia brasileira recrudesce, emergirão outras tantas descompensações sociais graduais, que a ocasião logo transformará em um desastre. Os perigos ditos 'naturais', na forma de secas ou enchentes atípicas, serão apenas o mote visível no território, pois, muito antes, o lugar já se sentirá, inseguro.

Por fim, mas não menos importante, Leroy (2014) enfatiza que por detrás da produção de simultâneos 'véus de normatização' (projetos de lei, portarias interministeriais, medidas provisórias, emendas constitucionais e afins), as forças políticas e econômicas dominantes no Brasil iniciam o século XXI com ânimo renovado rumo à flexibilização dos direitos dos povos tradicionais. No caso da Amazônia brasileira, são múltiplas as estratégias para, de um lado, legitimar a contestação de direitos territoriais de grupos sociais historicamente fragilizados e, de outro, anteparar-se no ideário desenvolvimentista para justificar a expansão da degradação socioambiental. Neste sentido, convém não desconsiderar os desastres silentes, a exemplo do ocorrido no Alto Juruá em 2008, como uma das práticas sociopolíticas que incorporam os dispositivos ambientais que fazem (e potencialmente farão ainda mais) submergir, literalmente, os povos da floresta.

\section{AGRADECIMENTOS}

As autoras agradecem à Regional do Instituto Chico Mendes de Conservação da Biodiversidade (ICMBio) de Cruzeiro do Sul e Marechal Thaumaturgo, que concederam a permissão para a realização da pesquisa na Reserva Extrativista Alto Juruá; à Secretaria de Estado de Extensão Agroflorestal e Produção Familiar de Marechal Thaumaturgo, pelas informações concedidas e apoio logístico propiciado em campo e aos demais parceiros que contribuíram direta e indiretamente para a realização desta pesquisa. 


\section{REFERÊNCIAS}

AGAMBEN, G. O que é um dispositivo? Outra travessia 5. Ilha de Santa Catarina, 2005. Disponível em: <https://periodicos.ufsc.br/index.php/Outra/article/ download/12576/11743>.

ASSIS, W. F., ZHOURI, A. - Representar Territórios e Des-figurar Conflitos Ambientais: O discurso do desenvolvimento sustentável na publicidade brasileira. Belém, Novos Cadernos NAEA - v. 14, n. 2, p. 117-140, dez. 2011, ISSN 1516-6481.

ATLAS DESENVOLVIMENTO HUMANO NO BRASIL. Marechal Thaumaturgo, 2013. Disponível em: <http://www.atlasbrasil.org.br/2013/perfil/>. Acesso em: 10 dez. 2013.

BOITO JR., A. As bases políticas do neodesenvolvimentismo. In: FÓRUM ECONÔMICO DA FGV, 2012. São Paulo. Anais... São Paulo: Fundação Getúlio Vargas, 2012. Disponível em: http://eesp.fgv.br/sites/eesp.fgv.br/files/file/ Painel $\% 20$ 3\%20- $\% 20$ Novo $\% 20$ Desenv $\% 20$ BR $\% 20-\% 20$ Boito $\% 20-\% 20$ Bases $\% \quad 20 \mathrm{Pol} \% 20$ Neodesenv\%20-\%20PAPER.pdf. Acesso em: 14 jan. 2013.

BRASIL. Ministério do Meio Ambiente. Instituto Chico Mendes de Conservação da Biodiversidade. Diretoria de Unidades de Conservação de Uso Sustentável e Populações Tradicionais. Termo de Referência para Elaboração do Plano de Manejo Participativo da Reserva Extrativista Alto Juruá/AC-Fase 1. Marechal Thaumaturgo: MMA/ICMBio/DIUSP, 2009. 13p.

BRASIL. Ministério do Meio Ambiente. Instituto Chico Mendes de Conservação da Biodiversidade. Plano de Manejo Participativo: Reserva Extrativista do Alto Juruá. Marechal Thaumaturgo: MMA/ICMBio, 2011.129 p.

BRASIL.Ministério da Integração Nacional. Secretaria Nacional de Defesa Civil. Centro Nacional de Gerenciamento de Riscos e Desastres. Anuário Brasileiro de Desastres Naturais: 2012. Brasília: CENAD, 2012. Disponível em: <http://www. integracao.gov.br/c/document_library/get_file?uuid=f22ccccd-281a-4b72-84b3654002cff1e6\&groupId=185960>. Acesso em: 5 abr. 2014.

CARDOSO, A. L. Risco urbano e moradia: a construção social do risco em uma favela do Rio de Janeiro. Cadernos IPPUR, Rio de Janeiro, v. 20, n. 1, p. 27-48, 2006.

DIEGUES, A. C. Etnoconservação: novos rumos para a conservação da natureza. São Paulo: NAQUPUB/USP, 2000.

EM-DAT. The OFDA/CRED International Disaster Database. Brussels: Université Catholique de Louvain, 2012. Disponível em: <www.emdat.br>. Acesso em: Acesso em: 14 jan. 2013.

FLORIANI, D. Diálogos interdisciplinares para uma agenda socioambiental: breve inventário do debate sobre ciência, sociedade e natureza. Desenvolvimento e Meio Ambiente, Curitiba, v. 1, n. 1, p. 21-39, 2000.

FOUCAULT, M. A ordem do discurso: aula inaugural no Collège de France, pronunciada em 2 de dezembro de 1970. São Paulo: Loyola, 1996. 
GUIVANT, J. S. A trajetória das análises de riscos: da periferia ao centro da teoria social. Revista Brasileira de Informação Bibliográfica em Ciências Sociais, Florianópolis, v. 1, n. 46, p. 3-37, 1998.

INGOLD, T. The perception of the environment: essays on livelihood, dwelling and skill. London: Routledge, 2000.

LEROY, J. P. Flexibilização de direitos e justiça ambiental. In: ZHOURI, A.; VALENCIO, N. (Orgs.). Formas de matar, de morrer e de resistir: limites da resolução negociada dos conflitos ambientais. Belo Horizonte: EdUFMG, 2014.

LITTLE, P. E. Territórios Sociais e Povos Tradicionais no Brasil: por uma antropologia da territorialidade. Brasília: Universidade Nacional de Brasília, 2002.

MARANDOLA Jr. E. A escolha de Sofia" ou o dilema da segurança humana nos desastres: qual agenda brasileira?. In: VALENCIO, N.; SIENA, M. (Orgs.). Sociologia dos desastres: construção, interfaces e perspectiva. São Carlos: RiMa, 2014.

MARENGO, J. A. Água e Mudanças Climáticas. Estudos Avançados, São Paulo, v. 22, n. 63, p. 83-96, 2008c. Disponível em: < http:/ /www.scielo.br/scielo.php?pid=S010340142008000200006\&script=sci_arttext>. Acesso em: 10 abr. 2013.

MARENGO, J. A. Hydro-climatic: and ecological behaviour of the drought of Amazonia in 2005. Philosophical Transactions of the Royal Society of London. Biological Sciences, London, v. 21, n. 1, p. 1-6, 2008a.

MARENGO, J. A.; NOBRE, C. A.; TOMASELLA, J.; OYAMA, M.; SAMPAIO, G.; OLIVEIRA, R. de; CAMARGO, H.; ALVES, L.; BROWN, I. The drought of Amazonia in 2005. Journal of Climate, v. 21, n. 1, p. 495-516, 2008b.

MARENGO, J. A. Interdecadal variability and trends of rainfall across the Amazon basin. Theoretical and Applied Climatology, v. 1, n. 78, p. 79-96, 2004.

MARENGO, J. A.; NOBRE, C. A.; CHOU, S. C.; TOMASELLA, J.; SAMPAIO, G.; ALVES, L.; OBREGÓN, G.; SOARES, W. Eventos extremos sazonais: secas de 2005 e 2010 e enchentes de 2009. In: Riscos das mudanças climáticas no Brasil. Análise Conjunta Brasil-Reino Unido Sobre os Impactos das Mudanças Climáticas e do Desmatamento na Amazônia. São José dos Campos: Instituto INPE, 2011. Disponível em: <http://www.inpe.br/noticias/arquivos/pdf/relatorioport.pdf>. Acesso em: 15 mar. 2013.

MARENGO, J. A.; VALVERDE, M. C. Mudanças na circulação atmosférica sobre a América do Sul para cenários futuros de clima projetados pelos modelos globais do IPCC Ar 4. Revista Brasileira de Meteorologia, São Paulo, v. 25, n.1, p. 125-145, 2010.

MARQUES, M. I. M. Lugar do modo de vida tradicional na modernidade. In. OLIVEIRA, A. U. de; MARQUES, M. I. M. (Orgs.). O campo no século XXI: território de vida, de luta e de construção da justiça social. São Paulo: Casa Amarela; Paz e Terra, 2004.

MESQUITA, É. Ver de perto pra contar de certo: as mudanças climáticas sob os olhares dos moradores da floresta do Alto do Juruá. 2012. 509f. Tese (Doutorado em Ciências Sociais) - Instituto de Filosofia e Ciências Humanas, Universidade Estadual de Campinas, Campinas, 2012. 
MORAES E SILVA, M.; CAPRARO, A. M.; SOUZA, J. de; MARCHI Jr., W. Norbert Elias e Michel Foucault - apontamentos para uma tematização relacional da noção de poder. INTERthesis Revista Internacional Interdisciplinar, Florianopolis, v. 11, n. 1, p. 254-275, 2014. Disponível em: <https://periodicos.ufsc.br/index.php/interthesis/ article/view/ 1807-1384.2014v11n1p254/26895>. Acesso em: 12 set. 2014.

ORGANIZAÇÃO DAS NAÇÕES UNIDAS-ONU. Aplicacion de la Estrategia Internacionale para la Reducción de los Desastres - Informe del Secretario General. Informe A/61/229, 2007. Disponível em: <http://www.unisdr.org/eng/ about_isdr/ basic_docs/SG-report/SG-report-61-229-pa.pdf>. Acesso em: 30 mar. 2013.

PLANO DE CONTINGÊNCIA DO MUNICÍPIO DE MARECHAL THAUMATURGO. Versão impressa. Marechal Thaumaturgo, 2012. Mimeo.

PORTAL DO GOVERNO DO ACRE. Municípios. 2014. Disponível em: < http:// www.ac.gov.br/wps/portal/acre/Acre/estado-acre/municipios $>$. Acesso em: 20 jan. 2014.

QUARANTELLI, E. L. Introduction: the basic question, its importance, and how it is addresses in this volume. In: QUARENTELLI, E. L. (Org.). What is a disaster? Perspective on the question. London; New York: Routledge, 1998.

QUARANTELLI, E. L. What is a disaster? New Answers to Old Questions. In: PERRY, R.; QUARANTELLI, E. L. (Orgs.). USA: International Research Committee on Disasters. [s.n.t.], 2005. 442 p.

SANTOS, M. A. dos. Natureza do Espaço. Técnica e Tempo. Razão e Emoção. São Paulo: Hucitec, 1997.

TUAN, Y-F. Paisagens do medo. São Paulo: EdUNESP, 2005.

UNITED NATIONS FRAMEWORK CONVENTION ON CLIMATE CHANGE. Climate Change: impacts, vulnerabilities and adaptation in developing countries. Climate Change Secretariat. Bonn: UNFCCC 2007. Disponível em: < http://unfccc.int/ resource/docs/publications/impacts.pdf>. Acesso em: 20 mar. 2014.

VALENCIO, N. F. L. da S. Desastres, ordem social e planejamento em Defesa Civil: o contexto brasileiro. Saúde e Sociedade, São Paulo, v. 19, n. 4, p. 748-762, 2010a.

VALENCIO, N. F. L. da S. O desastre como locus da barbárie: apontamentos sobre o caso brasileiro. In: VALENCIO N. (Org.). Sociologia dos Desastres: construção, interfaces e perspectivas no Brasil. São Carlos: RiMa, 2010b. p. 31-52.

VALENCIO, N. F. L. da S. Desastres, tecnicismo e sofrimento social. Ciência \& Saúde Coletiva, Rio de Janeiro, v. 19, n. 9, p. 3631-3644, 2014.

ZHOURI, A.; OLIVEIRA, R. Quando o lugar resiste ao espaço: colonialidade, modernidade e processos de territorialização. In: ZHOURI, A.; LASCHEFSKI, K. (Orgs.). Desenvolvimento e conflitos ambientais. Belo Horizonte: EdUFMG, 2010. 